\title{
A sonographic scoring system to assess the risk of thyroid malignancy
}

\author{
A A Pathirana ${ }^{1}$, K G M W Bandara ${ }^{1}$, MA Faleel ${ }^{1}$, S D Kuruppumullage ${ }^{1}$, N Solangarachchi ${ }^{1}$ \\ R Rupasinghe ${ }^{1}$, N P N Karunaratne ${ }^{1}$, D D Ranasinghe ${ }^{2}$, W A Epa ${ }^{2}$, V Thusyanthan ${ }^{1}$ \\ (Index words: thyroid malignancy, ultrasound characteristics, scoring system)
}

\begin{abstract}
Prediction of thyroid malignancy with fine needle aspiration cytology or individual ultrasound characteristics has several limitations. This study evaluates the usefulness of a combination of ultrasound characteristics in predicting malignancy in patients with thyroid nodules. We assessed 189 thyroid nodules using ultrasonography and histology. Each nodule was assigned a score based on ultrasonographic characteristics. This score was compared with histology to identify ability to predict malignancy. There were 28 malignant nodules. The scoring system was appropriate for clinical use, obtaining an area under ROC curve of 0.822 [ $p<0.0001] 95 \%$ confidence. FNAC of nodules with a score of more than 4 can be recommended $(100 \%$ sensitivity). Nodules with a score less than 8 can be offered total thyroidectomy when FNAC is inconclusive (97.5\% sensitivity). A combination of ultrasonographic criteria increase the accuracy of predicting malignancy in thyroid nodules.
\end{abstract}

Ceylon Medical Journal 2016; 61: 32-34

DOI: http://doi.org/10.4038/cmj.v61i1.8268

\section{Introduction}

Indications for thyroidectomy are many. A significant number of patients are offered surgery for suspicious cytology on fine needle aspiration cytology (FNAC) which is considered the most reliable investigation in the diagnosis of malignant thyroid nodules preoperatively [1]. Although pathologists have formulated a scoring system for thyroid cytology, there are several drawbacks [2]. For instance, follicular carcinoma can only be confirmed by histological means, as capsular or vascular invasion are the criteria to determine malignancy.

Malignancies in thyroid nodules could occur even in small nodules (less than $1 \mathrm{~cm}$ ). The aggressiveness has been found to be no different whether the nodules are palpable or not [3]. Therefore it is beneficial if the accuracy of pre-operative diagnosis could be improved in order not to miss malignant nodules and to offer surgery. Many imaging modalities of the thyroid have been evaluated. Radionuclide scans demonstrating “cold” nodules, once considered to be significant in predicting malignancy have been found to be unreliable [4].

Several studies have evaluated the usefulness of the ultra sound (US) examination of the thyroid. Although many US characteristics have been found to be associated with malignant lesions compared to benign lesions, combination of characteristics have not been assessed in prospective studies. US features that have a high predictive value include microcalcification, irregular margins, and intranodular vascularity [5]. Other characteristics which are considered suspicious include hypoechogenicity, taller-than-wide shape and a halo around the nodule [6]. Our study was aimed at assessing the usefulness of a combination of US characteristics (given a weightage score based on the significance) in predicting malignancy of thyroid nodules.

\section{Methods}

One hundred and thirty two consecutive patients with nodular (either solitary or multiple) goitres who were scheduled for thyroidectomy were included in this prospective study done between June 2009 and May 2012. There were 116 females. The mean age was 43.8 years (range 16-70). Indications for surgery were based on recognised criteria (suspicious or malignant FNAC, pressure effects or cosmetic reasons). Patients with goitres extending retrosternally or diffuse goitres were excluded.

The US examinations were performed by an experienced radiologist using a commercially available real time scanner (Toshiba Xario) equipped with a linear

${ }^{1}$ University Surgical Unit and ${ }^{2}$ Department of Radiology, Colombo South Teaching Hospital, Kalubowila, Sri Lanka. Correspondence: AP, e-mail: <aloka@slt.lk>. Received 27 October 2014 and revised version accepted 3 November 2015.

This is an open-access article distributed under the terms of the Creative Commons Attribution License, which permits unrestricted use distribution, and reproduction in any medium, provided the original author and source are credited. 
transducer operating at 6-8 MHz for morphological study. The recording of the findings as done on a purpose designed proforma ensuring uniform assessment. In patients with multi nodular goitres, up to three nodules greater than $1 \mathrm{~cm}$ diameter were evaluated. The proforma consisted of seven parameters. Each parameter was given equal weightage. But different characteristics of each parameter was assigned a weighted, relative point score according to the current supporting evidence for that characteristic and the degree to which it was felt to affect the pre-test probability for cancer. This was based on previously demonstrated relative risk, positive predictive value, and specificity of each characteristic for carcinoma. In general, scores of 0,1 , and 2 respectively, were given to factors considered to be mildly, moderately, and highly specific for thyroid carcinoma $[7,8]$. The appropriate score for each criterion was determined by the radiologist and each nodule was assigned a total score (Table 1). The total score on US ranged from 0 to 14 for the seven criteria.

The surgical specimens were marked for orientation when total thyroidectomy was performed. The diagnosis of cancer was based on histology. US and pathological findings were registered separately and blind-processed for statistical evaluation using xlstat 2015 version for

Table 1. Proposed scoring system using ultrasonographic features of thyroid

\begin{tabular}{|c|c|c|}
\hline Characteristics & & Score \\
\hline \multirow[t]{3}{*}{ Size } & AP*> width & 2 \\
\hline & $\mathrm{AP}=$ width & 1 \\
\hline & $\mathrm{AP}<$ width & 0 \\
\hline \multirow[t]{3}{*}{ Internal contents } & Solid & 2 \\
\hline & Mixed & 1 \\
\hline & Cystic thick wall & 0 \\
\hline \multirow[t]{3}{*}{ Echogenecity } & Hypoechoic & 2 \\
\hline & Isoechoic & 1 \\
\hline & Hyperechoic & 0 \\
\hline \multirow[t]{2}{*}{ Margins } & Ill-defined & 2 \\
\hline & Well defined & 0 \\
\hline \multirow[t]{3}{*}{ Calcification } & Microcalcification & 2 \\
\hline & Large coarse calcification & 1 \\
\hline & No calcification & 0 \\
\hline \multirow[t]{3}{*}{ Halo } & Thick & 2 \\
\hline & Thin & 1 \\
\hline & No & 0 \\
\hline \multirow[t]{4}{*}{ Vascularity } & Internal flow & 2 \\
\hline & Peripheral flow & 1 \\
\hline & No flow & 0 \\
\hline & Total score & 14 \\
\hline
\end{tabular}

* $\mathrm{AP}=$ anteroposterior
Microsoft excel application. Receiver operating characteristic (ROC) curve was drawn and sensitivity and specificity to detect malignancy at each score level was calculated. Approval for the study was obtained from the Ethics Review Committee of the Faculty of Medical Sciences, University of Sri Jayewardenepura.

\section{Results}

There were 36 patients with solitary nodules and 96 with multinodular goitres (153 nodules), with a total of 189 nodules. The majority of nodules were benign (161/189) on histology. Twenty eight patients had malignant nodules (Table 2). All nodules having a score greater than 9 were malignant and all with a score below 5 were benign (Table 3).

Table 2. Type of goitre vs histological type

\begin{tabular}{lccc}
\hline & Benign & Malignant & Total \\
\hline $\begin{array}{l}\text { Solitary nodule } \\
\text { Nodules of multi nodular }\end{array}$ & 16 & 12 & 28 \\
goitre & 145 & 16 & 161 \\
Total & 161 & 28 & 189 \\
\hline
\end{tabular}

Table 3. Coordinates of the ROC Curve

\begin{tabular}{rccccc}
\hline Score & $\begin{array}{c}\text { Sensi- } \\
\text { tivity }\end{array}$ & $\begin{array}{c}\text { Speci- } \\
\text { ficity }\end{array}$ & $P P V$ & NPV & $\begin{array}{c}\text { Accu- } \\
\text { racy }\end{array}$ \\
\hline 1 & 1.000 & 0.006 & 0.149 & 1.000 & 0.153 \\
2 & 1.000 & 0.031 & 0.152 & 1.000 & 0.175 \\
3 & 1.000 & 0.217 & 0.182 & 1.000 & 0.333 \\
$\mathbf{4}$ & $\mathbf{1 . 0 0 0}$ & $\mathbf{0 . 4 4 7}$ & $\mathbf{0 . 2 3 9}$ & $\mathbf{1 . 0 0 0}$ & $\mathbf{0 . 5 2 9}$ \\
5 & 0.643 & 0.720 & 0.286 & 0.921 & 0.709 \\
6 & 0.536 & 0.832 & 0.357 & 0.912 & 0.788 \\
7 & 0.536 & 0.932 & 0.577 & 0.920 & 0.873 \\
$\mathbf{8}$ & $\mathbf{0 . 4 2 9}$ & $\mathbf{0 . 9 7 5}$ & $\mathbf{0 . 7 5 0}$ & $\mathbf{0 . 9 0 8}$ & $\mathbf{0 . 8 9 4}$ \\
9 & 0.429 & 1.000 & 1.000 & 0.910 & 0.915 \\
10 & 0.321 & 1.000 & 1.000 & 0.894 & 0.899 \\
11 & 0.071 & 1.000 & 1.000 & 0.861 & 0.862 \\
12 & 0.036 & 1.000 & 1.000 & 0.856 & 0.857 \\
13 & 0.000 & 1.000 & & 0.852 & 0.852 \\
\hline
\end{tabular}

PPV - Positive predictive value

NPV - Negative predictive value

Test is positive if score $>$ threshold value

\section{Discussion}

Thyroid nodules are common and known to affect $20 \%$ to $76 \%$ of the population [3]. With US performed for unrelated neck symptoms, many patients are diagnosed with this condition incidentally. Although majority of these 
nodules are benign, some nodules can be malignant. The reported incidence of malignancies in operated thyroid nodules range from $6.5 \%$ to $40 \%$. This percentage increases (range 20\% - 40\%) when selection criteria for surgery is strict $[9,10]$. The proportion of malignant thyroids in our series (21\%) is therefore comparable to studies with strict selection criteria.

In the pre-operative evaluation of these nodules, although clinical evaluation is helpful, it is limited in most cases as many patients with malignant nodules have no overt clinical features of malignancy. FNAC is the only available test for malignancy. Although the cytological evaluation has improved with many guidelines being laid down to make assessment more uniform, its accuracy is low.

US evaluation using multiple criteria have been assessed but other than a few criteria which are known to increase the positive predictive value, none of them have been found to be of significant value when considered individually. Therefore a combination of US criteria was evaluated in this study. Giving a weightage for different characteristics helped to widen the range and therefore the accuracy. The criteria we used to evaluate nodules are already well-established and do not require any special training to master. The time spent and the need to remember fine details by the sonographer could be disadvantageous, but can be overcome by using a proforma. Area under the curve (AUC) is 0.822 . The computed $p$ value is $<0.0001$. Therefore this scoring system is reliable in predicting the outcome.

Based on the coordinates of the ROC (Table 4) two important decision making points can be recommended. First one is to select suspicious nodules for FNAC. As the score of 4 has a sensitivity of $100 \%$ it can be used to screen nodules for FNAC. Thus nodules with a score of $>4$ can be offered FNAC. The second is to decide on total or hemithyroidectomy especially when FNAC is inconclusive. As a score of 8 has $97.5 \%$ specificity for malignancy, nodules with a score of $>8$ can be offered total thyroidectomy especially when FNAC is inconclusive. The nodules with a score less than or equal to eight can be offered hemithyroidectomy.

In conclusion, using a multitude of radiological criteria increases the sensitivity and specificity of detecting thyroid malignancy. Combined with cytological findings these would strengthen the diagnostic power of preoperative investigations, and help in guiding clinicians to decide the appropriate type of thyroid surgery for goitres.

\section{Conflicts of interests}

There are no conflicts of interest.

\section{References}

1. Gharib H. Fine needle aspiration biopsy of the thyroid nodules: advantages, limitations and effect. Mayo Clinic Proc 1994; 69: 44-9. http://www.mayoclinicproceedings. org/article/S0025-6196(12)61611-5/pdf

2. Poller D, Cyiangon C, Cummings M, Botte D. Correspondence of thyroid FNA \& benign thyroid disease. Lancet 2000; 356: 679 .

3. Papini E, Guglielmi R, Bianchini A. Risk of malignancy in non-palpable thyroid nodules: predictive value of ultrasound and color-doppler features. Clin Endocrinol Metabol 2002; 87: 1941-6.

4. Kendall LW, Condon RE. Prediction of malignancy in solitary thyroid nodules. Lancet 1969; 293: 1071-3.

5. Takashima S, Fukuda H, Nomura N, et al. Thyroid nodules: Re-evaluation with ultrasound. Clin Ultrasound 1995; 23: 179-84.

6. Moon HJ, Kwak JY, Kim MJ, et al. Can vascularity at power doppler US help predict thyroid malignancy. Radiology 2010; 255: 260-9.

7. Rumack CM, Wilson SR, Charboneau JW. Diagnostic Ultrasound. $2^{\text {nd }}$ Edition. St. Mosby year Book Inc, Louis Missouri USA 1998, 718.

8. Sands NB, Karls S, Amir A, et al. McGill Thyroid Nodule Score (MTNS): "rating the risk" a novel predictive scheme for cancer risk determination. $J$ Otolaryngol Head Neck Surg 2011; 40 Suppl 1: S1-13.

9. Werk EEJ, Vernon BM, Gonzalez JJ, et al. Cancer in thyroid nodules. A community hospital survey. Arch Intern Med 1984; 144: 474-8.

10. Harach HR, Franssila KO, Wasenius VM. Occult papillary carcinoma of the thyroid. A "normal” finding in Finland. A systematic autopsy study. Cancer 1985; 56: 531-4. 